\title{
NOS LABIRINTOS DA EDUCAÇÃO: EXPERIÊNCIAS DE FORMADORAS EM FORMAÇÃO
}

Taluana Laiz Martins Torres ${ }^{1}$, Solange Estanislau dos Santos ${ }^{1}$

Doutoranda em Educação pela FCT/UNESP.E-mail: ttaluana@hotmail.com

\section{RESUMO}

Este artigo tem como objetivo discutir e problematizar nossas experiências de formação e pesquisa dentro de um programa federal que visava diminuir o analfabetismo de jovens e adultos no Brasil. $O$ trabalho desenvolveu-se a partir de acompanhamento do cotidiano escolar dos cursos de EJA, articulado à pesquisa-ação participante, refletindo e produzindo conhecimentos, na busca da construção de estratégias de intervenção na prática do trabalho pedagógico realizado. Se, por ora, o direito a aprender ler e escrever estava sendo garantido, ao menos teoricamente, com a implementação do programa, os direitos básicos para uma educação de qualidade precisavam ser constantemente negociados para que essa população tivesse acesso a recursos educacionais fundamentais. Tais obstáculos se colocam no caminho da EJA e reforçam a ideia de que o problema do acesso à educação de camadas populares não pode ser discutido de forma fragmentada, desconsiderando as condições objetivas produzidas por cada contexto local e global. Palavras-chave: formação; autoformação; EJA; alfabetização; pesquisa.

\section{INTRODUÇÃO}

Este texto tem como objetivo discutir e problematizar nossas ${ }^{1}$ experiências de formação e pesquisa dentro de um programa federal que visava diminuir o analfabetismo de jovens e adultos no Brasil.

O trabalho desenvolveu-se a partir de acompanhamento do cotidiano escolar dos cursos de educação de jovens e adultos - EJA - articulado à pesquisa-ação participante, refletindo e produzindo conhecimentos, na busca da construção de estratégias de intervenção na prática do trabalho pedagógico dos alfabetizadores que atuavam no curso.

Para além das experiências de pesquisa e formação inicial, resgataremos as sensações, medos, angústias e anseios de jovens estudantes que se encontravam em processo de formação, mas que também eram formadoras de educadores/as que atuavam no âmbito da alfabetização de jovens e adultos.

\footnotetext{
${ }^{1}$ Tratam-se das experiências das autoras do texto, que eram estudantes do curso de Pedagogia e integrantes do Programa Alfabetização Solidária, realizado no âmbito da Faculdade de Ciências e Tecnologia da Universidade Estadual Paulista - UNESP, campus de Presidente Prudente, no período entre 2002 e 2003.
} 


\section{Nos labirintos da educação: o fazer no Programa Alfabetização Solidária}

O labirinto é o lugar do estudo. Labor intus.Às vezes circular e unívoco, sem bifurcações [...] Aberto ao infinito. Às vezes multívoco, prolítico e indefinido. Um espaço de pluralização, uma máquina de desestabilização e dispersão, um aparato que desencadeia um movimento de sem-sentido, de desordem, de obscuridade, de expropriação.(LARROSA, 2003, p.31)

O Programa Alfabetização Solidária foi criado em 1997 com objetivo de reduzir os índices de analfabetismo entre jovens e adultos no Brasil, além de promover a oferta pública de educação para essa população. Assim, ele nasce a partir da iniciativa de uma Organização NãoGovernamental, sem fins lucrativos e de utilidade pública, tendo em vista a constatação da necessidade de oferta de EJA, já que os dados do Censo $\left(\right.$ IBGE $\left.^{2}\right)$ de 1991 indicavam a existência de cerca de 15 milhões de analfabetos no país. Atualmente, o Censo 2010 divulgou a existência de 13,9 milhões de analfabetos, ou seja, a queda foi pouco significativa e se mostrou aquém do esperado pelos/as estudiosos/as brasileiros/as.

A princípio, o programa foi executado a partir de parcerias mantidas com o Ministério da Educação - MEC, empresas, pessoas físicas, instituições de ensino superior, além de governos estaduais e municipais. Após certo período, o Alfabetização Solidária tornou-se um projeto do Governo Federal em parceria com as Universidades brasileiras e procurava responder as demandas de analfabetismo de jovens e adultos nas regiões onde os índices eram mais elevados. Nesse contexto, o papel das Universidades era executar as atividades de alfabetização desenvolvidas, desde a seleção e capacitação dos alfabetizadores até o acompanhamento e avaliação dos cursos oferecidos.

A equipe da Universidade era composta por uma professora coordenadora ${ }^{3}$ e por alunos/as provenientes de diferentes cursos, embora a maior participação fosse das alunas do curso de Pedagogia. Mais especificamente, nosso trabalho enquanto alunas e integrantes do programa, estava voltado à seleção dos/as alfabetizadores/as que atuariam nos municípios de Buritinópolis/GO e Itabaianinha/SE, capacitação ${ }^{4}$ dos educadores selecionados, orientação mensal através de visitas aos municípios e salas de aula, preparação dos materiais didáticos para uso dos/das alfabetizadores/as e organização de eventos na qual pudéssemos trocar experiências e conhecer atividades desenvolvidas na região do oeste paulista no âmbito da alfabetização de

\footnotetext{
${ }^{2}$ Instituto Brasileiro de Geografia e Estatística.

${ }^{3}$ No referido período a coordenadora era a Profa. Dra. Maria Peregrina de Fátima Rotta Furlanetti.

${ }^{4}$ Os cursos de capacitação tinham duração de aproximadamente quinze dias e eram realizados na Faculdade de Ciências e Tecnologia - UNESP, em Presidente Prudente/SP. Para tal capacitação elaborávamos com antecedência uma apostila com materiais teóricos e práticos, que eram entregues aos alfabetizadores.
} 
jovens e adultos. Contávamos ainda com reuniões semanais com a professora coordenadora e toda a equipe para discutir o andamento do trabalho, bem como para a realização de leitura, pesquisas e estudos voltados à educação de jovens e adultos.

Desse modo, esses espaços de socialização se configuravam também como lugares de formação, já que a partir deles nossas experiências se transformavam em ponto de partida para a reflexão e questionamento da realidade vivida, já que, segundo Paulo Freire (1996, p.38): “a prática docente crítica, implicante do pensar certo, envolve o movimento dinâmico, dialético, entre o fazer e o pensar sobre o fazer", ou seja, o grupo funcionava como uma comunidade de interpretação, como espaço de produção de significados e alargamento de sentidos referentes a EJA, uma vez que a educação é: "um espaço de integração e criação de novas formas de convívio e de sociabilidade, um vasto campo de possibilidades de experiências, aprendizados, confrontos, afetos e sentidos" (LEITÃO, 2004, p.35).

Assim, a participação nessa experiência de extensão universitária nos permitia o contato direto com eixos considerados fundamentais na formação do/a professor/a: o ensino e a pesquisa, essenciais para que nossa curiosidade ingênua se transformasse em curiosidade epistemológica, como nos lembra Freire (1996, p.29): “Não há ensino sem pesquisa nem pesquisa sem ensino. Ensino porque busco, porque indaguei, porque indago e me indago. Pesquiso para constatar, constatando intervenho, intervindo educo e me educo". Além disso, esse movimento dialético entre ensino e pesquisa também nos proporcionou um conhecimento abrangente das iniciativas, problemas e discussões travadas na educação de jovens e adultos no Brasil, de modo que a pesquisa-ação participativa permitiu estabelecer um diálogo permanente entre educadores e educandos, possibilitando um rico intercâmbio com os vários sujeitos que participavam do processo educativo, por meio do estudo e da reflexão coletiva sobre o cotidiano escolar.

Mas, qual seria o maior propósito desse tipo de programa? Quais os benefícios que um programa de alfabetização em massa traz para esses sujeitos? Por que a educação brasileira precisa, ainda hoje, de alternativas paliativas que deem conta do grande número de cidadãos que não foram alfabetizados? Seria possível, promover uma educação crítica, assim como afirmava Adorno (1971 apud MAAR, 2002, p.61)?

[...] concebo como sendo educação a produção de uma consciência verdadeira. Esta teria simultaneamente grande significado político. Isto é: uma democracia que não se propõe a apenas funcionar, mas proceder de acordo com seu conceito, exige homens emancipados. Uma democracia realizada só pode ser concebida como sociedade de quem é emancipado. 
Nesse sentido, todas as decisões referentes as estratégias adotadas por nós, formadores/as, eram debatidas nas reuniões e acordadas democraticamente, ou seja, o grupo discutia os problemas e dificuldades enfrentados e sugeriam soluções e possibilidades de intervenção e pesquisa, visando produzir novos conhecimentos a respeito daquela realidade. Mais ainda, as discussões de questões de ordem prática eram sempre permeadas por estudos teóricos embasados nas ideias do educador Paulo Freire, que nos ajudava a pensar soluções para as problemáticas que envolviam todo o grupo.

\section{Formação e autoformação: discussão dos percursos trilhados e os saberes construídos}

Os processos de formação estão relacionados ao que saber, por que saber e aos modos de saber na relação entre as pessoas. (LEITÃO, 2004, p.28 grifos nossos).

Essa citação nos revela um aspecto importante da formação, a relação entre as pessoas. E foi justamente assim que ocorreu o nosso processo formativo: nas relações que fomos estabelecendo com os/as educadores/as, os/as alfabetizandos/as, entre os pares e com a coordenadora do programa. Foi no movimento de erros e acertos, angústias e esperanças que fomos nos constituindo enquanto formadoras, pesquisadoras e agentes de mudança. Pois, como bem afirma Leitão (2004, p.28): "Se entendemos a relação com os saberes constituída também de afeto, curiosidade e provisoriedade, esse entendimento traz em seu interior incertezas e necessidade de mudanças, e com elas perdem-se algumas certezas".

As trocas de experiências entre os membros do programa ocorriam em espaços diversos, contudo, as reuniões semanais na qual estavam presentes tanto os/as monitores/as (alunos/as) quanto a professora coordenadora, eram momentos de encontros essenciais para a discussão e tomada de decisões a respeito do andamento do trabalho. Nessas reuniões conversávamos sobre as capacitações, visitas realizadas aos municípios, o trabalho e desempenho dos/as professores/as-alfabetizadores/as nas salas de aula e nas reuniões pedagógicas que oferecíamos, o envolvimento dos/as educandos/as, as dificuldades encontradas por nós, da universidade, e por eles, professores e educandos dos municípios atendidos, analisando os sucessos e as dificuldades. Tais discussões eram permeadas pela realidade dos/as alunos/as alfabetizandos/as que, em sua maioria, eram provenientes das áreas rurais dos municípios. Vale dizer ainda que as salas de alfabetização do programa, em sua maioria, também eram situadas na zona rural, na qual os 
índices de analfabetismo são apontados como mais elevados, exigindo um planejamento diferenciado, voltado a essa população.

As visitas aos municípios de Buritinópolis/GO e Itabaianinha/SE eram realizadas mensalmente e havia um revezamento entre os/as monitores/as (alunos/as) do projeto no intuito de que todos conhecessem a realidade do município trabalhado. Esse acompanhamento realizado pelos monitores/as permitia observar melhor o desenvolvimento do trabalho planejado, possibilitando a elaboração de estratégias mais coerentes com a realidade local. Em geral, permanecíamos entre dois e quatro dias no município, dependendo das atividades planejadas nas reuniões e realizávamos visitas às salas em funcionamento (tanto na área urbana como na rural) e reuniões pedagógicas com os/as professores/as alfabetizadores/as.

Muitas eram as dificuldades vivenciadas nessas visitas e, de modo geral, alguns problemas de ordem estrutural eram recorrentes nos municípios participantes do programa: muitas salas, algumas até mesmo improvisadas, ainda não contavam com iluminação, pois não havia energia elétrica no local, enquanto outras eram iluminadas por lampiões. Mesmo quando havia energia, chegamos a encontrar situações em que na sala tinha apenas uma lâmpada e a falta de iluminação dificultava, quando não impedia o trabalho do professor. Essa situação se agravava quando tomávamos conhecimento de que a maioria dos/as alfabetizandos/as eram idosos e tinham problemas de visão. Essa era uma das principais causas de desistência relatadas pelos/as próprios/as alunos/as do programa.

Como a iluminação era de responsabilidade das prefeituras, em nossas visitas sempre conversávamos com os secretários de educação sobre a questão, no intuito de resolver o problema. Percebemos que os municípios onde a parceria com as prefeituras eram mais sólidas, o problema era sanado, entretanto, esse era um elemento que demorava certo tempo para ser solucionado, enquanto isso as aulas eram ministradas mesmo diante dessa grande dificuldade. $\mathrm{O}$ que é possível pensar que, apesar desses percalços, como salienta Leitão (2004, p.33), é necessário "incorporar no processo formativo os próprios impasses e contradições das práticas educativas. Isto é profundamente desestabilizador, mas nos permite criar um espaço de confronto, [...] O confronto, nessa perspectiva, é inevitável e saudável, pois é parte inerente desse processo".

Outra questão de ordem prática que dificultava o andamento do trabalho estava relacionada ao problema de visão de muitos/as alunos/as idosos/as, embora houvesse um acordo entre prefeitura e governo estadual para que eles pudessem ter acesso aos exames oftalmológicos e 
óculos gratuitos, isso demorava a acontecer. Tal situação se prolongou durante todo o funcionamento do programa e os/as alunos/as se queixavam muito com os monitores, já que o prefeito explicava que os óculos não eram de sua responsabilidade e que a prefeitura não tinha condições de arcar com essas despesas.

Esses problemas se repetiam a cada visita e como não competia a universidade, o que podíamos fazer era apenas cobrar dos representantes governamentais medidas efetivas para resolver essas questões. Entretanto, esses elementos muitas vezes impossibilitavam nosso trabalho, pois como poderíamos de fato executar um trabalho de qualidade se condições mínimas não eram oferecidas para os/as alunos/as aprenderem? Qual professor/a conseguiria alfabetizar um educando numa sala de aula sem iluminação?

Isso nos leva a refletir com Leitão (2004, p.35) quando afirma que “[...] a complexa e difícil arte de educar, de produzir e criar sentidos perpassa o campo da formação/autoformação e nos indaga a respeito de sua possibilidade de emancipação". Ou seja, a negação de condições mínimas para o exercício da cidadania estavam presentes a todo momento e fugiam de nossa área de atuação, mas não da nossa reflexão e da construção concreta de ideias educacionais. Fazia parte do exercício de reflexão a recusa aos fatalismos de uma ordem perversa, que minimizava os seres humanos. Por esse motivo, a resistência e insistência para resolução de questões que impediam o funcionamento das atividades eram constantes e compartilhadas com educandos e educadores.

Se, por ora, o direito a aprender ler e escrever estava sendo garantido, ao menos teoricamente, com a implementação do programa, os direitos básicos para uma educação de qualidade precisavam ser constantemente negociados para que essa população tivesse acesso a recursos fundamentais como um local adequado para aprender, acesso a saúde pública, transporte, alimentação etc. Estes eram obstáculos que se colocavam no caminho da educação de jovens e adultos e reforçava a ideia de que o problema do acesso à educação de camadas populares não pode ser discutido de forma fragmentada, desconsiderando as condições objetivas produzidas por cada contexto local e global. Leitão (2004, p.28) salienta: “O campo da educação de jovens e adultos está repleto de desafios. Um deles é a contradição entre as leis que regem a área e as políticas governamentais de caráter compensatório, que atribuem à EJA um papel menor".

Se, por um lado, faltavam investimentos em áreas consideradas fundamentais, recursos financeiros eram aplicados em outras atividades. Isso levava ao questionamento, por nós, monitores/as, da divisão e aplicação dos recursos, já que julgávamos ser imprescindível a 
discussão e tomada de decisão, entre todos os envolvidos - planejadores, executores e alunos do programa - das prioridades na aplicação das verbas.

As capacitações eram prova de investimento maciço, pois em muitas delas todos os cerca de trinta futuros/as alfabetizadores/as, selecionados/as nos municípios parceiros, eram trazidos de avião para Presidente Prudente e hospedados por cerca de quinze dias em hotéis da cidade. A justificativa para que as capacitações fossem realizadas nos municípios das universidades, com a necessidade de deslocamento de muitos professores, era de que não havia estrutura necessária para a realização das atividades de capacitação no próprio município de origem dos alfabetizadores. E de fato não havia, contudo, todo esse investimento não seria contraditório se contraposto a falta de estrutura em que eram ministradas as aulas?

As capacitações eram ministradas pelos/as monitores/as, sob a coordenação da professora responsável e contavam com aulas, seminários, elaboração de atividades e passeios. Essa era sempre uma atividade que gerava angústia nos monitores, já que o tempo de duração da capacitação era insuficiente para a formação de um/uma professor/a alfabetizador/a competente, apesar de todo planejamento e elaboração de materiais, trabalho que demandava meses de dedicação de nós, monitores/as.

No curso realizávamos estudos teóricos sobre temas ligados a realidade dos educadores e educandos como: cidadania, leitura, escrita, direitos humanos, entre outros. A preparação do curso e dos materiais foram essenciais em nosso processo de formação, já que estes eram a base para a elaboração de um saber que se voltava sempre para a prática pedagógica e nos desafiava a criar estratégias coerentes com o público-alvo. Pensar uma formação de qualidade implicou desenvolver capacidades analíticas e de tomada de decisão, interiorizando conhecimentos, aprendendo a lidar com situações complexas e até mesmo contraditórias o que permitiu a construção de um trabalho coletivo, na definição de metas e estabelecimento de compromissos.

Outra medida contraditória que o programa adotava era o "rodízio de professores/as" a cada seis meses. Ou seja, o/a alfabetizador/a, independente do sucesso de seu trabalho, era dispensado e outro/a assumia em seu lugar, sendo que o profissional não tinha oportunidade de se aperfeiçoar a partir de sua experiência, pois logo era substituído por outro. Essa prática gerava atrito entre a universidade e as instituições parceiras, que não abriam mão de mudanças nessa área, justificando que esse seria um modo de dar mais oportunidades para a população ingressar no programa e receber "qualificação" docente. 
Assim, sempre nos questionávamos sobre a real intenção do programa: seria mesmo o de contribuir para a diminuição do número de analfabetos/as no Brasil? Será que os/as alunos(as)/ alfabetizandos(as) eram o objetivo principal da existência do Alfabetização Solidária? Até quando as decisões mais abrangentes e importantes seriam tomadas por setores superiores, alheios a realidade local na qual o programa atuava?

Não temos a resposta para essas questões, mas o que podemos analisar de toda experiência é que enquanto houver a separação entre aqueles que "tomam as decisões" e os que "planejam e/ou executam" as ações educativas, haverá sempre contradição.

Mais preocupante ainda é constatar que a situação da educação de jovens e adultos no Brasil não destoa, em todos os sentido, da educação nacional, como salienta Lopes et al (2009, p.98): "Ainda não galgamos o patamar do todo/tudo em educação, ainda estamos vislumbrando uma quase-cidadania, uma quase-educação[...] ]enfim, uma quase-democracia".

Por isso nunca encontrávamos a saída desse labirinto, estávamos sempre recomeçando do zero, retornando os corredores desconhecidos, que não sabíamos para onde nos levariam.

Entretanto, apesar de todos os percalços, idas e vindas, tal experiência nos permitiu construir saberes indispensáveis a qualquer educador e educadora comprometidos/as com uma educação emancipatória. Lapidou o nosso olhar para as políticas públicas educacionais, nos possibilitando vivenciar as contradições e armadilhas presentes em estratégias que, apesar de caminhos tortuosos e destino duvidoso, as relações de reciprocidade estabelecidas entre as pessoas envolvidas enriqueceram nossas trajetórias de vida: “[...] pois não basta só escolher o caminho, mas fazê-lo e refazê-lo ao caminhar". (LEITÃO, 2004, p.35).

\section{REFERÊNCIAS}

FREIRE, Paulo. Pedagogia da autonomia: saberes necessários à prática educativa. São Paulo: Paz e Terra, 1996. 165p. (Coleção Leitura).

FREIRE, Paulo. Professora sim, tia não. São Paulo: Olho d'água, 1997.

LARROSA, Jorge. Pedagogia profana: danças, piruetas e mascaradas. 4.ed. Belo Horizonte: Autêntica, 2003.

LEITÃO, Cleide Figueiredo. Buscando caminhos nos processos de formação/autoformação. Revista Brasileira de Educação. n.27, set-dez, 2004.

LOPES, E.C.C.; LIMA, A.B. de; SHIMAMOTO, S.V.M. As políticas de gestão educacional no município de Uberlândia/MG: concepções de democratização. In: LIMA, Antonio Bosco (Org.). Estado e controle social no Brasil. Uberlândia: FAPEMIG, 2009. 
MAAR, W. L. Educação Crítica, Formação Cultural e Emancipação Política na Escola de Frankfurt. In: PUCCI, B.(org.). Teoria Crítica e Educação : a questão da formação cultural na Escola de Frankfurt. Petrópolis: Vozes, 2002, p.61- 81. 